\title{
In the Climate Emergency, Conservation Must Become Survival Ecology
}

\author{
Charlie J. Gardner ${ }^{1 *}$ and James M. Bullock ${ }^{2}$ \\ ${ }^{1}$ Durrell Institute of Conservation and Ecology, University of Kent, Canterbury, United Kingdom, ${ }^{2}$ Faculty of Science and \\ Technology, Bournemouth University, Poole, United Kingdom
}

\section{OPEN ACCESS}

Edited by:

Xingli Giam,

The University of Tennessee,

United States

Reviewed by:

Lise Comte,

Illinois State University, United States

Simone Fattorini,

University of L'Aquila, Italy

*Correspondence:

Charlie J. Gardner

cjamgardner@yahoo.co.uk

Specialty section:

This article was submitted to Global Biodiversity Threats,

a section of the journal

Frontiers in Conservation Science

Received: 28 January 2021

Accepted: 29 September 2021

Published: 28 October 2021

Citation:

Gardner CJ and Bullock JM (2021) In

the Climate Emergency, Conservation

Must Become Survival Ecology.

Front. Conserv. Sci. 2:659912.

doi: 10.3389/fCosc. 2021.659912
Earth faces a climate emergency which renders conservation goals largely obsolete. Current conservation actions are inadequate because they (i) underplay biodiversity's role in maintaining human civilisation, which contributes to its marginalisation, and (ii) rely on false assumptions of how to catalyse transformative change. We suggest a paradigm shift from biodiversity conservation to survival ecology, refocusing the field on safeguarding a planetary system in which humans and other species can thrive. Rather than seeking to maintain a world which will no longer exist, survival ecology acknowledges unavoidable change and seeks to shape the world that will: it looks to the future, not the past. Since conservation science and advocacy have not been sufficient to achieve the required change, survival ecologists should additionally embrace non-violent civil disobedience.

\section{Keywords: biodiversity, climate, civil disobedience, collapse, conservation, extinction, social movement}

\section{INTRODUCTION}

Climate change threatens to end human civilisation (Richards et al., 2021), and almost 14,000 scientists have declared "clearly and unequivocally that planet Earth is facing a climate emergency" (Ripple et al., 2021). An emergency is a critical situation requiring our immediate attention; in an emergency, we stop what we were doing and refocus on the urgent task at hand. However, like most of society, conservation stakeholders (including scientists, practitioners, policy-makers, and funders) have collectively failed to respond to the urgency of the emergency and adapt our objectives and approaches. Here, we argue that climate risks are so great as to render largely obsolete the customary conservation focus on preventing species extinctions and maintaining the current benefits people obtain from nature. Instead, we suggest that conservation aims may best be achieved by refocusing and reframing conservation around the safeguarding of an Earth system that supports both human civilisation and other life into the future, a paradigm we term "survival ecology." We first make the case that near-future impacts of climate change on biodiversity will be so severe that the conservation movement needs to re-examine its fundamental objectives. We then argue that reframing conservation around a survival ecology agenda may be required to transition the field from its currently marginal status to the heart of economic and political decision-making. However, while our argument largely concerns conservation's framing, the transition to survival ecology also requires fundamental changes to conservation philosophies, objectives, practise, and theories of change, which we briefly outline in the following two sections. We do so in the hope of stimulating an urgently-needed debate, because without rapid adaptation to the climate emergency and reflection on its continued inability to catalyse the required changes in our economies and societies, conservation will fail to conserve global biodiversity. 


\section{BIODIVERSITY IN THE CLIMATE EMERGENCY}

Conservation is a diverse field encompassing a range of rationales and approaches (Sandbrook et al., 2019). While rationales for conservation have become increasingly anthropocentric over recent decades, it remains largely centred (and, in particular, marketed) on the goal of maintaining biodiversity through the prevention of species extinctions (e.g., Bolam et al., 2020; Rounsevell et al., 2020). However, existing efforts have failed to prevent extensive anthropogenic biodiversity loss driven by habitat change, overharvesting, species introductions and cascading effects (Secretariat of the Convention on Biological Diversity, 2020; Bradshaw et al., 2021), and an estimated one million species now face extinction (Díaz et al., 2019). Moreover, the prospects for preventing further extinctions become ever more remote in the climate emergency, as an increasing body of evidence highlights the negative impacts of climate change on species and ecosystems in all biomes. For example, temperature increases and other climatic changes will render large portions of the current ranges of many species unsuitable within decades (e.g., Román-Palacios and Wiens, 2020; Trisos et al., 2020), but many species will be unable to adapt sufficiently (Radchuck et al., 2019) or shift their ranges within these timeframes (Román-Palacios and Wiens, 2020). This of course supposes the existence and accessibility of suitable niche space elsewhere, though this will be particularly lacking for many montane and polar species, and island endemics (La Sorte and Jetz, 2010; Post et al., 2019; Veron et al., 2019). Further, temporal adaptations will cause increasing phenological mismatches between currently interacting species (Kharouba et al., 2018), hastening the breakdown of biotic communities and amplifying extinction risks. All major ecosystems will undergo major transformation (Nolan et al., 2018), though tropical biomes such as humid forests and coral reefs are particularly threatened (Trisos et al., 2020). While these direct impacts are likely to affect most if not all species and ecosystems, they will also serve as a multiplier of existing threats (such as habitat change and overharvesting), as human societies take actions to mitigate and adapt to changes already underway (Watson, 2014). Thus, climate change is expected to drive rapid increases in species extinction risk (Urban, 2015; Román-Palacios and Wiens, 2020).

While conservation was failing to arrest biodiversity loss even before climate impacts started to become apparent, it is now clear that climate change will be so severe as to threaten the survival of entire biomes and condemn many species to extinction regardless of any future conservation efforts. The principal conservation objective of preventing extinctions is built on the assumption that all species can be saved from extinction, yet climate change renders this largely obsolete. Given that existing conservation efforts, which were already failing, will be inadequate in the face of climate impacts, the continuation of the current conservation paradigm is not an option and the field must rapidly adapt its objectives and strategies. But while the climate emergency necessitates an evolution in conservation, it also presents an opportunity to mainstream conservation by reframing the field as critical to the maintenance of human civilisation, as well as other species.

\section{FROM BIODIVERSITY CONSERVATION TO SURVIVAL ECOLOGY}

According to the lead authors of the Intergovernmental SciencePolicy Platform on Biodiversity and Ecosystem Services (IPBES), preventing catastrophic climate change and reversing other drivers of biodiversity loss will require "transformative change, namely a fundamental, system-wide reorganisation across technological, economic, and social factors, making sustainability the norm rather than the altruistic exception" (Díaz et al., 2019). However, conservation largely continues to portray and market itself as an "altruistic exception" by framing the field as the endeavour to prevent extinctions of other species. This is problematic because, while many decision-makers may agree that conserving species is a noble goal, few behave as if it is essential. As a result, conservation remains an economically and socially marginal activity; for example, protected areas are our principal conservation strategy but global protected area spending is estimated at US\$24.3 billion/year (Waldron et al., 2020), the size of the global beard grooming industry (Thomas and Deshmukh, 2019). Simply put, conservation is not a priority for our societies, and neither the public nor political leaders understand the gravity of the threat biodiversity loss poses for humanity (Bradshaw et al., 2021).

Conservation should be ultimately about much more than preventing the extinction of threatened species, because the promotion of complex, well-functioning and resilient ecosystems ensures the generation of ecosystem services that underpin human wellbeing in the present (Díaz et al., 2019), and is a key strategy for both mitigating and adapting to (Malhi et al., 2020) the catastrophic climate change that threatens the survival of human civilisation. If we are to persuade society to take conservation seriously, we must stop framing it as the altruistic quest to save other species from extinction, and instead present it as the selfish, pragmatic goal of sustaining the conditions for human civilisation and other life on Earth. Given that climate change renders the objective of preventing all species extinctions impossible, the goal of conservation should be to retain, into the future, an Earth system in which life (including human life) can flourish. In other words, we must dynamically maintain, restore and create ecosystems to allow the biosphere to evolve, adapt and change such that it maintains itself in all its complexity during a time of rapid biotic and abiotic change. We must move from biodiversity conservation to survival ecology.

While the survival ecology framing has some echoes of other approaches which centre conservation around explicitly anthropocentric concerns, including ecosystem services ("ES," Millennium Ecosystem Assessment, 2005), nature's contributions to people ("NCP," Díaz et al., 2018), and natural climate solutions ("NCS," Griscom et al., 2017), it differs fundamentally in three respects. Firstly, while the ES, NCP and NCS frameworks focus on the specific components of biodiversity that generate desired services, survival ecology instead focuses on the conditions that allow them (or any other, less service-generating components 
of biodiversity) to thrive, and strives for resilient and adaptable ecosystems that benefit all species, including humans. Rather than focusing on elements of the Earth system that are of value to people, survival ecology requires managing the system as a whole. Secondly, survival ecology recognises that a focus on present values (which is the predominant focus of ES and NCP) is inappropriate in a time of rapid global change, and is explicitly forward-looking. Thirdly, existing frameworks do not address the question of how conservation itself needs to change, while survival ecology recognises the need for new philosophies and approaches (which we discuss in the following sections).

Some authors have argued that utilitarian rationales for conservation have partly contributed to to the ecological crisis, and thus that anthropocentric framings carry risks (Taylor et al., 2020). However, the ecocentric arguments central to conservation have been equally unsucessful in persuading society of the importance of the living world. In this regard, nothing conservationists have tried so far has worked, but it would be foolish to stop trying new approaches in an emergency context. Moreover, while survival ecology is somewhat anthropocentric in framing, it is neither anthropocentric nor ecocentric in practise because, as the IPBES lead authors state, "maintaining a life-sustaining and life-fulfilling planet for humans and other species are [...] one and the same challenge" (Díaz et al., 2019). Nevertheless, survival ecology is more than just a reframing of conservation for marketing purposes or asking people to ascribe monetary value to biodiversity. It also requires a fundamental shift in conservation philosophies and approaches, and in particular a re-examination of our atttutide to biotic change (Figure 1).

\section{FROM REACTIVE TO PROACTIVE}

Conservation is a dynamic, evolving field and some efforts have been made to adapt it to the rapidly changing climate. These include the NCS approach to maximise conservation's contribution to climate mitigation, and efforts to enhance the resilience of approaches such as protected areas. However, rapid adaptation to the climate emergency remains hampered the field's prevailing attitude to change. Conservationists have generally sought either to prevent change (by combatting anthropogenic threats to maintain species and ecosystems as they are now), or to reverse it (by restoring species populations and ecosystems to some desired past state). However, given the inevitability of widespread climate-driven abiotic change, including considerable extinctions, we must cease looking to the past for our benchmarks, and instead think to the future (Thomas, 2020). Conservation time and resources spent on trying to maintain the world as it currently is, or recently was, risk being wasted because that world will soon no longer exist, if indeed it still does. While it is of course desirable to maintain as much of current biodiversity as possible, and a comprehension of current and past ecosystems may inform future actions, the goal of maintaining ecosystems as they are, or restoring them to how they used to be, is simply not possible in a rapidly changing climate. Failure to acknowledge that, and refocus conservation objectives in response, risks wasting conservation time and resources on quixotic quests. Conversely, letting go of the past must not lead to a laissez faire attitude to future change. We need to plan proactively, by defining the future we want, researching what is needed to get there, and starting to actively manage both species and ecological and evolutionary processes to influence the outcomes of unavoidable environmental change. We must stop working to conserve a world that will no longer exist, and start trying to shape the one that will.

One key way in which this proactive approach will manifest itself is in our attitudes to the distribution of life on Earth, and our concepts of native and non-native species. The introduction of invasive non-native species has been a major driver of extinctions and other biodiversity impacts (Pyšek et al., 2020), so the deliberate translocation of species is risky and controversial. However, given the mass of extinctions projected this century as a result of species' inabilities to track or adapt to climate change (Román-Palacios and Wiens, 2020), assisted colonisation on a massive scale (Butt et al., 2020) will likely be required within decades. This may even require the active establishment of entire ecosystems in novel places-if coral reefs and tropical humid forests will no longer occur in their current locations, should we not make efforts to ensure they exist somewhere? These activities could also promote evolution and speciation in the new environments, potentially leading to the maintenance of biological complexity (Hendry et al., 2017). Given that this will necessarily entail the creation of novel ecosystems, a regulatory framework and enhanced research agenda will be required.

Of course, for many ecosystems we lack the ecological knowledge to be able to intervene in this way and be confident of the outcomes, though restoration ecology can give pointers as to how to assemble new ecosystems, and evidence for novel ecosystems shows that new combinations of species can assemble communities successfully (Kennedy et al., 2018). While such "experimentation" does represent a leap in the dark to some extent, when one is in a burning building the only choice is to leap. Climate change is already a huge experiment with the future of life on Earth, and no non-radical choices remain. The only options are to continue as normal with conservation mindsets developed in the climatically-stable world we have left behind, or to adapt our approaches and develop solutions explicitly designed to overcome the problems at hand. Nevertheless, even such radical changes in conservation approaches will be insufficient unless we also reconsider how conservation seeks to influence political and economic decision-making, and wider society.

\section{FROM ADVOCATES TO ACTIVISTS}

Conservation science largely operates according to an unspoken "theory of change" (ToC) that if we generate scientific information about biodiversity loss and its implications, and develop solutions, society's leaders will use that information to make wise policy decisions, and fund the implementation of those solutions. However, this $\mathrm{ToC}$ is based on false assumptions, and conservation is failing (just as climate change is occurring) because scientists have not adequately considered 


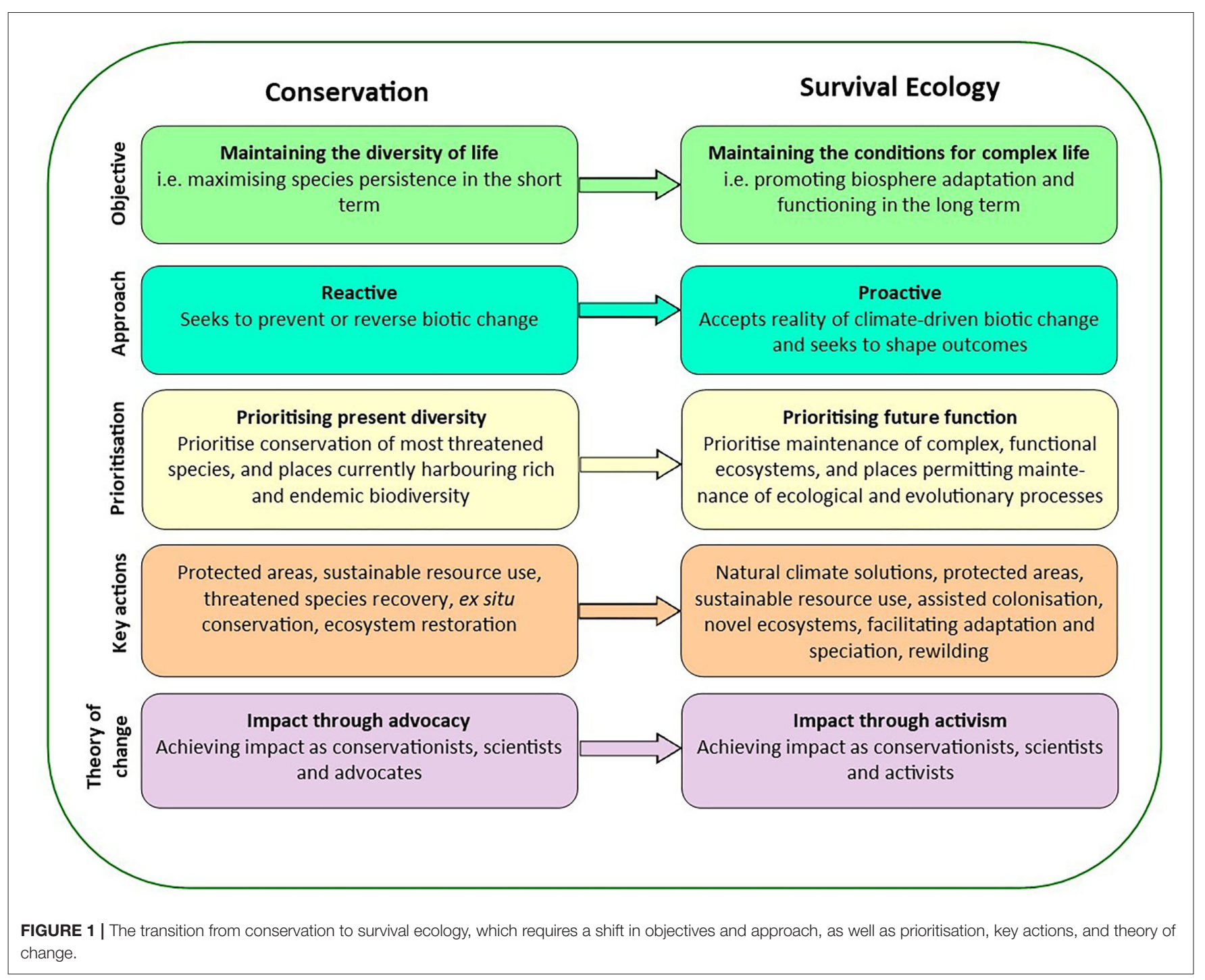

how social and political change occurs in the real world (Gardner et al., 2021). Conservation science alone cannot determine governmental policy-making and funding decisions because these are additionally influenced by the lobbying, donations and public relations campaigns of billion-dollar industries including agrochemicals, industrial meat production, fisheries, logging, plastics, mining, construction, and so on. Since the science and practise of conservation have not and cannot be enough to bring about the required transformative changes in our economic systems, survival ecology (or any appropriate response to an emergency context) requires that we should additionally engage in efforts with a higher chance of success.

Direct activism such as non-violent civil disobedience has historically been effective in bringing about political change (Chenoweth and Stephan, 2012), and played an important role in the successful struggles for universal suffrage in the UK, civil rights in the USA, and independence from colonialism in many countries. Since 2018 it has also succeeded in raising climate change up the media, public and political agenda, through the actions of movements such as Fridays for Future, Extinction Rebellion and others. For example, numerous countries have declared a climate emergency, and in 2019 the environment grew to become the third largest concern for British voters (Gardner and Wordley, 2019). However, the increase in public, media and political concern has been heavily weighted towards climate, and the parallel issue of biodiversity loss has been overshadowed (Gardner et al., 2020). Similar efforts are required for the living world, and these may be lent important credibility and authority should scientists participate publicly as scientists, rather than simply as citizens (Gardner et al., 2021).

Such is the primacy of the science-to-policy change ToC in conservation that some suggest conservation scientists should refrain even from advocacy for fear of reducing their scientific legitimacy or authority (see e.g., Lackey, 2007; Chan, 2008). However, conservation science is an explicitly normative and value-laden discipline: it sees biodiversity as good, and strives to maintain it (Noss, 2007). To achieve this objective, conservationists have a long history of extending beyond 
research to engage in both conservation practise and advocacy. Indeed, it is common for conservation scientists to work for, collaborate with, or receive funding from non-governmental and campaigning organisations adopting the explicit political position that biodiversity should be prioritised in decisionmaking, or advocating for one species (or site, or conservation method) over others. Values and advocacy are thus integral to conservation, and to claim scientists and the science they do are value-neutral risks undermining the public's trust and acceptance of that science (Oreskes, 2019). However, while conservation scientists have long engaged in advocacy, neither that nor our research and practise have been sufficient to slow the destruction of nature appreciably (Secretariat of the Convention on Biological Diversity, 2020; Bradshaw et al., 2021) and they will prove increasingly inadequate as the climate emergency deepens. In this emergency, we must think beyond approaches that have proved inadequate to date. If we are to move conservation issues to the mainstream of public and political thought, and trigger the transformations required to maintain most life on Earth, we will need to become more influential. If conservation was content with advocacy, the twin climate and ecological emergencies require survival ecologists to go one step further, and become activists.

\section{DISCUSSION AND CONCLUSIONS}

Conservation, we believe, is in need of radical reform because it is unable to achieve its goals in the present, and will be increasingly unable to do so in a rapidly changing future. By largely focusing on and marketing itself as the conservation of other species it has constrained itself to being only peripherally relevant to human society, and in seeking to prevent biotic change it has burdened itself with a goal rendered impossible by climate change. By reframing goals around the maintenance of an Earth system in which both humans and other species can survive (and hopefully thrive), we believe that the field will be better able to mainstream itself into political and economic decision-making, and avoid wasting effort and resources on endeavours that will ultimately prove futile.

Some of our suggestions may be controversial, not least the notion that preventing species extinctions is no longer

\section{REFERENCES}

Bolam, F. C., Mair, L., Angelico, M., Brooks, T. M., Burgman, M., Hermes, C., et al. (2020). How many bird and mammal extinctions has recent conservation action prevented? Conserv. Lett. 14:e12762. doi: 10.1111/conl. 12762

Bottrill, M. C., Joseph, L. N., Cawardine, J., Bode, M., Cook, C., Game, E. T., et al. (2008). Is conservation triage just smart decision making? Trends Ecol. Evol. 23, 649-654. doi: 10.1016/j.tree.2008.07.007

Bradshaw, C. J. A., Ehrlich, P. R., Beattie, A., Ceballos, G., Crist, E., Diamond, J., et al. (2021). Underestimating the challenges of avoiding a ghastly future. Front. Conserv. Sci. 1:615419. doi: 10.3389/fcosc.2020.615419

Butt, N., Chauvenet, A. L. M., Adams, V. M., Beger, M., Gallagher, R. V., Shanahan, D. F., et al. (2020). Importance of species translocations under rapid climate change. Conserv. Biol. 35, 775-783. doi: 10.1111/cobi.13643 necessarily an appropriate goal. However, it has long been recognised that not all species can be saved, and discussions over conservation triage were underway long before the extent of climate impacts on biodiversity became apparent (Bottrill et al., 2008). The ES, NCP, and NCS frameworks imply that species not contributing to the delivery of particular services should be deprioritised, though survival ecology makes no such value judgements and recognises the role of all species in maintaining complex and resilient ecosystems. It does, however, acknowledge the inevitability of extinctions, and emphasises the maintenance of an Earth system in which species can adapt and new species can evolve, to counter that loss.

We seek only to stimulate an urgently-needed debate on how to conserve biodiversity in a rapidly-changing world, and it is beyond this essay to propose any plan of implementation. Indeed survival ecology cannot necessarily even be "implemented," for it is a way of thinking about conservation rather than a plan or toolbox. Many of the tools and techniques developed by conservationists will clearly remain essential to the survival ecology agenda. For example, we will still need to manage protected areas, restore ecosystems, and empower local communities to manage natural resources sustainably. However, these and other traditional approaches will never be sufficient while they are implemented in pursuit of an objective that is both impossible to achieve and considered trivial by society. In the climate emergency, we can no longer conserve all biodiversity. Instead we must aim to maintain the planetary conditions that will allow both humans and other species to thrive.

\section{AUTHOR CONTRIBUTIONS}

CG conceived the paper. CG and JB wrote the paper. Both authors contributed to the article and approved the submitted version.

\section{ACKNOWLEDGMENTS}

CG thanks Sophus zu Ermgassen for stimulating discussion of some of the ideas in this paper.

Chan, K. M. A. (2008). Value and advocacy in conservation biology: crisis discipline or discipline in crisis? Conserv. Biol. 22, 1-3. doi: 10.1111/j.1523-1739.2007.00869.x

Chenoweth, E., and Stephan, M. J. (2012). Why Civil Resistance Works: The Strategic Logic of Nonviolent Conflict. New York, NY: Columbia University Press.

Díaz, S., Pascual, U., Stenseke, M., Martín-López, B., Watson, R. T., Molnár, Z., et al. (2018). Assessing nature's contributions to people. Science 359, 270-272. doi: $10.1126 /$ science.aap 8826

Díaz, S., Settele, J., Brondízio, E. S., Ngo, H. T., Agard, J., Arneth, A., et al. (2019). Pervasive human-driven decline of life on Earth points to need for transformative change. Science 366:eaax3100. doi: 10.1126/science.aax3100

Gardner, C. J., Struebig, M. J., and Davies, Z. G. (2020). Conservation must capitalise on climate's moment. Nat. Commun. 11:109. doi: 10.1038/s41467-019-13964-y 
Gardner, C. J., Thierry, A., Rowlandson, W., and Steinberger, J. K. (2021). From publications to public actions: the role of universities in facilitating academic advocacy and activism in the climate and ecological emergency. Front. Sustain. 2:679019. doi: 10.3389/frsus.2021.679019

Gardner, C. J., and Wordley, C. F. R. (2019). Scientists must act on our own warnings to humanity. Nat. Ecol. Evol. 3, 1271-1272. doi: 10.1038/s41559-019-0979-y

Griscom, B. W., Adams, J., Ellis, P. W., Houghton, R. A., Lomax, G., Miteva, D. A., et al. (2017). Natural climate solutions.. Proc. Natl. Acad. Sci. U.S.A. 114, 11645-11650. doi: 10.1073/pnas.1710465114

Hendry, A. P., Gotanda, K. M., and Svensson, E. I. (2017). Human influences on evolution, and the ecological and societal consequences. Phil. Trans. R. Soc. B 372:20160028. doi: 10.1098/rstb.2016.0028

Kennedy, P. L., Fontaine, J. B., Hobbs, R. J., Johnson, T. N., Boyle, R., and Lueders, A. S. (2018). Do novel ecosystems provide habitat for wildlife? Revisiting the physiognomy vs. floristics debate. Ecosphere 9:e02172. doi: 10.1002/ecs2.2172

Kharouba, H. M., Ehrlén, J., Gelman, A., Bolmgren, K., Allen, J. M., Travers, S. E., et al. (2018). Global shifts in the phenological synchrony of species interactions over recent decades. Proc. Natl. Acad. Sci. U.S.A. 115, 5211-5216. doi: 10.1073/pnas.1714511115

La Sorte, F. A., and Jetz, W. (2010). Projected range contractions of montane biodiversity under global warming. Proc. R Soc. B 277, 3401-3410. doi: $10.1098 /$ rspb. 2010.0612

Lackey, R. T. (2007). Science, scientists, and policy advocacy. Conserv. Biol. 21, 12-17. doi: 10.1111/j.1523-1739.2006.00639.x

Malhi, Y., Franklin, J., Seddon, N., Solan, M., Turner, M. G., Field, C. B., et al. (2020). Climate change and ecosystems: threats, opportunities and solutions. Phil. Trans. R Soc. B 375:20190104. doi: 10.1098/rstb.2019.0104

Millennium Ecosystem Assessment (2005). Ecosystems and Human Well-Being: Synthesis. Washington, DC: Island Press.

Nolan, C., Overpeck, J. T., Allen, J. R. M., Anderson, P. M., Betancourt, J. L., Binney, H. A., et al. (2018). Past and future global transformation of terrestrial ecosystems under climate change. Science 361, 920-923. doi: $10.1126 /$ science.aan5360

Noss, R. F. (2007) Values are a good thing in conservation biology. Conserv. Biol. 21: $18-20$.

Oreskes, N. (2019). Why Trust Science? Princeton, NJ: Princeton University Press.

Post, E., Alley, R. B., Christensen, T. R., Macias-Fauria, M., Forbes, B. C., Gooseff, M. N., et al. (2019). The polar regions in a $2^{\circ} \mathrm{C}$ warmer world. Sci. $A d v$. 5:eaaw9883. doi: 10.1126/sciadv.aaw9883

Pyšek, P., Hulme, P. E., Simberloff, D., Bacher, S., Blackburn, T. M., Carlton, J. T., et al. (2020). Scientists' warning on invasive alien species. Biol. Rev. 96, 1511-1534. doi: 10.1111/brv.12627

Radchuck, V., Reed, T., Teplitsky, C., van de Pol, M., Charmantier, A., Hassall, C., et al. (2019). Adaptive responses of animals to climate change are most likely insufficient. Nat. Commun. 10:3109. doi: 10.1038/s41467-019-1 0924-4

Richards, C. E., Lupton, R. C., and Allwood, J. M. (2021). Re-framing the threat of global warming: an empirical causal loop diagram of climate change, food insecurity and societal collapse. Clim Change 164:49. doi: 10.1007/s10584-021-02957-w

Ripple, W. J., Wolf, C., Newsome, T. M., Gregg, J. W., Lenton, T. M., Palomo, I., et al. (2021). World scientists' warning of a climate emergency 2021. BioScience 71, 894-898. doi: 10.1093/biosci/biab079
Román-Palacios, C., and Wiens, J. J. (2020). Recent responses to climate change reveal the drivers of species extinction and survival. Proc. Natl. Acad. Sci. U.S.A. 117, 4211-4217. doi: 10.1073/pnas.1913007117

Rounsevell, M. D. A., Harfoot, M., Harrison, P. A., Newbold, T., Gregory, R. D., and Mace, G. D. (2020). A biodiversity target based on species extinctions. Science 368, 1193-1195. doi: 10.1126/science.aba6592

Sandbrook, C., Fisher, J. A., Holmes, G., Luque-Lora, R., and Keane, A. (2019). The global conservation movement is diverse but not divided. Nat. Sustain. 2, 316-323. doi: 10.1038/s41893-019-0267-5

Secretariat of the Convention on Biological Diversity (2020). Global Biodiversity Outlook 5. Montreal, QC: Secretariat of the Convention on Biological Diversity.

Taylor, B., Chapron, G., Kopnina, H., Orlikowska, E., Gray, J., and Piccolo, J. J. (2020). The need for ecocentrism in biodiversity conservation. Conserv. Biol. 34, 1089-1096. doi: 10.1111/cobi.13541

Thomas, A., and Deshmukh, R. (2019). Beard Grooming Market: Global Opportunity Analysis and Industry Forecast, 2019-2026. Pune: Allied Market Research. Available online at: https://www.alliedmarketresearch.com/beardgrooming-market (accessed August 6, 2021).

Thomas, C. D. (2020). The development of Anthropocene biotas. Philos. Trans. $R$ Soc. B 375:20190113. doi: 10.1098/rstb.2019.0113

Trisos, C. H., Merow, C., and Pigot, A. L. (2020). The projected timing of abrupt ecological disruption from climate change. Nature 580, 496-501. doi: $10.1038 /$ s41586-020-2189-9

Urban, M. (2015). Accelerating extinction risk from climate change. Science 348, 571-573. doi: 10.1126/science.aaa4984

Veron, S., Mouchet, M., Govaerts, R., Haevermans, T., and Pellens, R. (2019). Vulnerability to climate change of islands worldwide and its impact on the tree of life. Sci. Rep. 9:14471. doi: 10.1038/s41598-019-51107-x

Waldron, A., Adams, V., Allan, J., Arnell, A., Asner, G., Atkinson, S. et al. (2020). Protecting 30\% of the Planet for Nature: Costs, Benefits and Economic Implications. Washington, DC: Campaign for Nature. Available online at: https://www.conservation.cam.ac.uk/files/waldron_report_30_by_ 30_publish.pdf (accessed August 6, 2021).

Watson, J. E. M. (2014). Human responses to climate change will seriously impact biodiversity conservation: it's time we start planning for them. Conserv. Lett. 7 , 1-2. doi: $10.1111 /$ conl. 12083

Conflict of Interest: The authors declare that the research was conducted in the absence of any commercial or financial relationships that could be construed as a potential conflict of interest.

Publisher's Note: All claims expressed in this article are solely those of the authors and do not necessarily represent those of their affiliated organizations, or those of the publisher, the editors and the reviewers. Any product that may be evaluated in this article, or claim that may be made by its manufacturer, is not guaranteed or endorsed by the publisher.

Copyright (c) 2021 Gardner and Bullock. This is an open-access article distributed under the terms of the Creative Commons Attribution License (CC BY). The use, distribution or reproduction in other forums is permitted, provided the original author(s) and the copyright owner(s) are credited and that the original publication in this journal is cited, in accordance with accepted academic practice. No use, distribution or reproduction is permitted which does not comply with these terms. 